\title{
Diversity management in the workplace: beyond compliance
}

\author{
NS Gwele, RN, PhD \\ Executive Dean; Faculty of Health Sciences, Durban University of Technology
}

\section{Kev words}

diversity management, cultural diversity, workplace diversity

\section{Correspondence address}

Prof Nomthandazo S Gwele, Dean: Faculty of Health Sciences Durban University of Technology POBox 1334

Durban 4001

Tel:(031) 373-2407

Fax: (031) 373-2407

E-mail: Gwele(a)dut.ac.za

\section{Abstract: Curationis 32 (2): 4-10}

Diversity management is not a numbers game. Diversity management is a holistic and strategic intervention aimed at maximizing every individual's potential to contribute towards the realization of the organization's goals through capitalizing on individual talents and differences within a diverse workforce environment. Managing interpersonal relationships within a diverse workforce environment presents a number of challenges related to changes in the social, legal and economic landscape, individual expectations and values as well as the inevitable change in organizational culture (Chartered Institute of Personnel and Development 2005: 1-7). Whether or not organizations are effective in managing diversity is a function of senior managements' commitment, and the perceived centrality of diversity management by all those who populate the institution's workspace. Above all it should be clear to all employees, irrespective of race, gender, or vocational/professional status, that each and every one of them has something of value to contribute towards the realization of the institution's mission and goals.

It is crucial to determine clear and manageable success indicators, focusing not only on compliance with legal obligations to include and/or increase the number of employees from the underrepresented and designated groups, but also on strategic intervention strategies to be used to promote and nurture individual talent and potential toward the realization of both individual aspirations and organizational goals re-quality patient outcomes.

\section{Introduction}

Diversity management has its roots in the human resources movement in the United States of America. The concept emerged because it was no longer believed that affirmative action was achieving its intended consequences, that is, equality of opportunity in the workplace (Chartered Institute of Personnel and Development [CIPD] 2005: 8-13). Yet, Human (1996: 46) argues that managing diversity is the competence required for the effective implementation of affirmative action. Viewed from Human's perspective therefore, managing diversity is distinct and different from affirmative action, yet an essential competence for the realization of its outcomes. Numerous conceptualizations of the construct exist in the literature. It is not the purpose of this paper to engage in the merits and demerits of such conceptualizations. Nevertheless, several authors agree (CIPD 2005; Friday \& Friday 2003; Human 1996) that managing diversity in the workplace is not an event but a complex and a dyn.mic process that requires periodic ruvies and strategic intervention. Essentially, managing diversity involves a departure from collective views of groups of people to valuing individual differences and talent in the workplace. More succinctly, "managing diversity is more than simply acknowledging differences in people. It involves recognizing the value 
of differences, combating discrimination and promoting inclusiveness" (Green et al. 2002:2).

\section{Source and/or types of diversity}

Diversity in itself is a simple concept to understand. It refers to nothing more than variance or difference. What complicates the management of the difference is not the difference itself, but the nature and the meaning of the difference as perceived by the individual and others. According to Esty et al. (1995) cited in Green et al. (2002:1) diversity refers to "acknowledging, understanding, accepting, valuing, and celebrating differences among people with respect to age, class, ethnicity, gender, physical and mental ability, race, sexual orientation, spiritual practice and public assistance status". The CIPD (2005: 25) presents an elegant, yet succinct approach to understanding diversity. According to the CIPD, types of diversity include (a) social category diversity, (b) organizational diversity, and (c) value diversity. Social category diversity includes differences in demographic characteristics such as age, gender, and race. To this list, I would add ethnicity and culture. Organizational diversity on the other hand includes differences characterized by educational levels, function and tenure, whereas value diversity may refer to psychological differences in personality and attitudes (CIPD 2005: 25). Within the context of this paper, diversity refers to "any attribute that happens to be salient to an individual that makes him/her perceive that he/she is different from another individual" (William \& O'Reilly1997, cited in Friday \& Friday 2003: 863).

\section{Understanding and respecting cultural diversity in clinical setting}

The organizers of the $2^{\text {nd }}$ Biannual Nursing Managers' Summit had tasked me to talk specifically about managing cultural diversity in the clinical setting. This indeed was a tall order on two accounts. Firstly, I cannot remember when last I was in the clinical setting. I accepted this task on the assumption that the clinical setting in South Africa at least, presents similar yet particular challenges to diversity management as any other workplace. Secondly, the complexity of the concept of culture, and its inextricable association with race within the South African context makes for a challenging topic of engagement. Issues of race in the workplace are not comfortable topics of engagement; perhaps because segregation and discrimination in South Africa were based on race. A detailed account of the extensiveness of racial oppression and its pervasiveness in all forms of societal life and engagement in South Africa appears in the United Nations' 1985 article 40/64 on 'Policies of apartheid of the Government of South Africa' (General Assembly, UN; 1985:32-40). Desegregation and diversifying the workplace, must of necessity involve racial desegregation as well as other forms of difference such as disability and gender.

For many South Africans, the change of government in 1994 signalled an end to racial oppression and discrimination and the beginning of an era marked by equality of opportunity and access to employment. Regrettable, as noted by a number of authors (Human 1996: 46/ 57; Sacht n.d.: 1; Tshikwatamba 2003: 36 ) this dream has yet to fully materialize. Human (1996: 46) further asserts that "South Africa, unlike some other countries of the world, has no choice but to manage workforce diversity and to manage it effectively". For this reason, whilst acknowledging that culture is more than race, and includes other forms of difference such as religion and language, this paper is premised on my understanding that it is impossible to separate issues of race and culture in conversations surrounding managing diversity in the South African workplace, whether in the clinical setting or otherwise. Just what is meant by cultural diversity presents its own set of theoretical complexities and problematic.

\section{Culture as Problematic}

A number of authors bemoan the confusion often made between managing diversity and managing culture (Fitzgerald 1997: 1; Human 1996:51-59). Harris and Moran (1989), cited in Fitzgerald (1997:1) define culture as "communicable knowledge for human coping within a particular environment that is passed down for the ben- efit of subsequent generations". According to Fitzgerald (1997:1) this anthropological definition of culture as advanced by Harris and Moran (1989) makes it clear that culture is on the whole very slow to change, and is cumulative and conservative. Similar views were posited by Human (1996: 51-59) in her analysis of two ends of the continuum of theoretical explanations of culture: the maximalist or universalistic view and the minimalist or particularistic view. According to her, the roots of the former can be traced to the definition of culture by Hofstede in the mid 1980s and 1990s, who sees culture as "the collective programming of the mind which distinguishes one group of people from another" (Human 1996: 52). According to Human (1996: 56) the minimalist view is often attributed to the multiculturalist perspective, which places emphasis on celebrating the differences. She nevertheless attests that both views present their own set of problems for those involved in diversity management.

Whilst acknowledging the usefulness of the traditional maximalist stereotypical view of culture, in helping us make sense of the world, the danger of overreliance on stereotypes is that they are very resistant to change and that "initial classification of people or objects into groups often leads to an assignment of status based on power relations" (Human 1996: 56). The result of this is the view that some groups are inherently superior to others, with concomitant negative or positive self-fulfilling prophecies affecting work performance and development (Human 1996:56).

At the other end of the continuum, the minimalist approach sees culture as a function of interaction between individuals and that "culture constitutes a subconscious part of the person's identity as a communicator and is contracted to a large extent by the perception of the other party in the interaction" (Human 1996: 51). The proponents of the minimalist view of culture use the multicultural approach to diversity training and management. The emphasis is on celebrating the differences. Taken to the extreme the minimalist view of culture can lead to the denial of that which is common to us all as populations of nation states 
or just as human beings. In this regard Fitzgerald (1997:3) warns that "there must ... be understanding and appreciation of 'fundamental differences' between groups - cultural or otherwise - with an emphasis on diversity. But there must also be recognition of 'fundamental similarities,' cultural universals that link us to a common humanity".

Importantly however, we cannot deny that "cultural background is one of the primary sources of identity. It is the source for a great deal of self-definition, expression and sense of group belonging" (Ayton-Shenker 1995: 1). Understanding and respecting cultural diversity in the workplace, therefore must of necessity be premised on the understanding that people do belong to groups, and that to a large extent, their identities are defined by their traditional culture. But as noted by others, cross-cutting social variables such as education, social class, level of modernization, language group, regional and political differences (de Haas 1990; cited in Human 1996: 53) as well as "ethnic awareness and perceived differences of gender or sexual orientation" (Fitzgerald, 1997, p. 3) create an ongoing process of interaction and intermingling of cultures leading to changed cultural identities (Ayton-Shenker, 1995:1).

Managing cultural diversity in the clinical setting must focus not on collectives but on valuing individuals and creating environments conducive to the maximizing of individual development and potential, irrespective of group membership. It is not about affirmative action or equal opportunities simple aimed at getting the numbers 'right'. Managing diversity is about accepting that all employees, professional and non-professional, from the cleaning staff to the chief executive officer can contribute positively towards the realization of the institution's mission and goals. In a clinical setting the quality of patient outcomes is the most critical organizational goal. The quality of patient outcomes, however, is as much the function of the quality of interpersonal working relationships of the staff as well as the quality of vocational and/or professional expertise. It is the responsibility of senior management and all line managers to create "a culture of mutual respect and the realisation that valuing cach $\mathrm{cm}$ ployee's differences can bring strength and synergy to groups, teams, departments and ultimately the organization as a whole" (CIPD 2005: 11).

\section{Understanding and dealing with challenges of cultural diversity}

Most literature on managing cultural diversity cmanates from private organizations. It is acknowledged that South Africa is rich in both its private and public health sector. Public and private metropolitan clinical settings experience similar diversity challenges. Much of the private industry literature on diversity management exalts the benefits of a diverse workforce. These benefits centre on the belief that individual differences create the potential for a more creative and different way of thinking about organizational issues and thus should lead to innovative solutions to routine problems. Additionally, within the clinical setting context, it is believed that the diverse patient population would be better served by a diverse staff. There is the danger however, of romanticizing an extremely complex and demanding process, which as noted by Tshikwatamba (2003:36) "despite their advantages in the work place ... differences are sometimes the source of considerable hostility and disagreements".

That cultural differences and religious beliefs have been the cause of much hostility and human suffering globally, is a matter of public knowledge. The clinical setting is but a small aspect of the world in which we live and work. Within the clinical environment, cultural differences can be found in both traditional cultures and the 'new' cultural identities resulting from the socialization and inculcation processes encountered in the professional schools that produce those who populate the clinical setting. So then, what are some of the challenges that are associated with managing diversity in the clinical setting? The CIPD (2005: 6-7) identifies a number of factors that impact on the management of a workforce. Those which are relevant to this paper include (a) changes in the social, and legal landscape, (b) the psychological contract, and (c) cultural and organiza- tional changes.

\section{Changes in the Social and Legal Landscape}

Affirmative action and employment equity are legislated mechanisms which aim to create a fully inclusive work environment in South Africa. "Employers have been forced by law to accelerate the hiring of a more diverse workforce and to remove the barriers to employment progress for previously disadvantaged groups" (Sacht, n.d.:1). No industry, including the clinical setting, is excluded from the legal requirement to ensure a demographically diverse workforce. In a country with a history of legal racial segregation of the workplace, the challenge is to ensure that institutions go beyond compliance and create environments that are conducive to effective contribution of all employees toward the realization of the institution's mission and goals.

Desegregation of health care settings with the concomitant inclusion of all South African population groups in institutions previously segregated along racial lines, for access and staffing, presents a uniquely South African challenge for diversity management. Many health care professionals, used to work with colleagues and provide care to patients whose way of life was similar to theirs and who spoke the same language. Suddenly these workers are faced with a diverse hospital population (patients and staff) whose way of life is markedly different from the dominant Western health care model of our health care settings. For cxample, there are patients who do not speak the same language as the professionals that care for them. The result is that most health care professionals are caring for patients whose complex needs are very difficult, if not impossible, to understand or recognize. The professionals are working with colleagues whose individual differences, beyond the stereotypical classifications they grew up with as well as those learned at medical and/or nursing school, continue to be a mystery.

Hiring more people from the previously disadvantaged groups will not and cannot of itself ensure that these diverse groups of people work together effectively (Human 1996: 46; Sacht n.d.: 1). Strategic and concerted efforts must 
be made to ensure that all employees have a fair and equitable chance to compete for the few promotional positions. Although a number of institutions have initiated diversity management training, often in the form of once-off workshops, concerted and ongoing efforts at cducation and training are not evident. Perhaps, because of tight budgets, and cost cutting within a financially stretched health care environment, "the extra effort, which focuses on diversity training and interpersonal learning, is still viewed as an optional extra" (Sacht n.d.: 1). Yet, still it could be that, health care organizations, having satisfied themselves that they have managed to get the demographics "correct", feel that their job is done because the statistics shows that they comply with legislation.

Within the health care industry, rescarch and academic inquiry have focused mainly on cultural competence as this relates to patient care. Little, if any work has been done on the interpersonal relations and the meaning of diversity among the employees. More importantly, South African researchers, managers and scholars in the health care industry, are deafeningly silent about the state of managing diversity in both the public and the private health sector. A study conducted by Aries (2004: 172-180) involving senior managers, line managers, patients and frontline workers in six hospitals in the United States of America revealed that although cultural competence was viewed as critical for patient care, understanding its meaning was determined by one's role. For instance, Aries reported that senior managers were satisfied that the hospital took cultural competence seriously because most materials such as procedure manuals had been translated into the most common languages used in the region, translation for patients was available when needed, and culturally diverse staff was employed. Patients and frontline workers however, believed that cultural biases were seen as embedded in the day -to- day functioning of the hospital.

Pointedly, "senior managers were most concerned with developing positive relations with communities surrounding the hospitals, creating a physical environment that was accommodating to patients' cultural beliefs and practices, adapting hospital policies to be culturally responsive, hiring a diverse workforce that paralleled that of the communities served" (Arics 2004: 174). Line managers had total responsibility for interpreting and implementing the hospitals' policies on cultural diversity and competence and saw any conflicts among staff as personality related rather than culture based. Frontline workers "felt that racial and cultural stereotyping existed throughout the hospital and that it negatively affected the work environment" (Arics 2004: 178).

\section{The Psychological Contract}

The CIPD (2005: 7) defines the psychological contract as the unwritten contract between the individual and the employer. The changing workplace environment and the diminishing opportunities for jobs for life has led to a situation in which employees are looking for short-term rather than long-term rewards. According to the CIPD, personal development and work-life balance are high on today's employees' expectations. Employers who do not recognize this are faced with high staff turn-over. Loyalty to the company is no longer a factor determining whether to stay or leave. Nowadays, "employees expect to be treated fairly and are less tolerant of sharp employment practices or poor pay or working conditions" (CIPD 2005: 7). These observations are no different from the current experiences in the health sector. Literature on the migration of health care professionals cites poor working conditions, poor pay and lack of opportunities for development and advancement as the main contributory factors for leaving the country (Gwele 2003: 812). A high staff turnover at a time when institutions are trying to create effective interpersonal working relationships in a diverse workforce environment presents a challenge for diversity management.

\section{Cultural and Organizational Changes}

The pace and the complexity of organizational change, especially the kind brought about by mandatory and legislated diversity might be too fast and too much for some. Toffler in his 1970 bestseller "Future Shock" draws a dis- tinction between culture shock and future shock (CIPD 2005: 7). In Future shock, when the future comes too soon, long before the individual can cope with it, the result is psychological and biochemical stresses- manifesting themselves occasionally in "violence or apathy" (ISI, 1982: 20). In culture shock, individuals may decide to go back to their traditional culture, if they feel they cannot cope with the new culture. In the rapidly changing organizational cultures and the characteristics of the people who populate the workplace, the old and familiar may no longer be available for "culturally shocked" employees to return to (CIPD 2005: 7). In South Africa, for some employees, the legal requirement for a diverse workforce came too soon. For them, Culture shock has become Future shock. The challenge therefore, is to establish $\mathrm{cm}$ ployec assistance avenues and/or opportunities to help them deal with the realities of diversity in the workplace and help them see and understand that "there is no going back". Hostilities, anger, and apathy are some of the challenges that manifest themselves in interpersonal relations in diverse work environments, especially among those for whom diversity came too soon. The question then becomes what strategies institutions can use to create effective working environments with a diverse workforce.

\section{A strategic approach to manageing diversity in the workplace}

The internet is awash with a list of tabulated "sure fire" strategies for effective management of diversity from well meaning diversity consultants, academics and social commentators. Yet, the CIPD (2005: 9) warns that, "the notion of best practice, while helpful in a theoretical setting, won't provide all the answers in reality. There isn't a single right way of treating employees as each one will have their own personal needs, values and beliefs, which they will articulate, hoping they can be met at least in part". Hence, I will be guided by a futuristic conceptualization of diversity management as "making quality decisions in the midst of differences, similarities and tensions" (Thomas 2006: 46). In line with a number of authors in the field (CIPD 2005: 1-55; 


\section{Macro-Level Arguments}

- National Policy and Regulatory Framework on:

o Human rights and the Constitution

o Affirmative Action and Equal Opportunities Act

o Batho Pele- Principles

o Professional and Ethical Codes of Conduct

\section{Organizational Level Arrangements}

- $\quad$ The Current Situation in the Institution

o Patient demographics and perceptions about the institution's performance in cultural competence

o Surrounding communities' perceptions about the intuition's performance in cultural competence

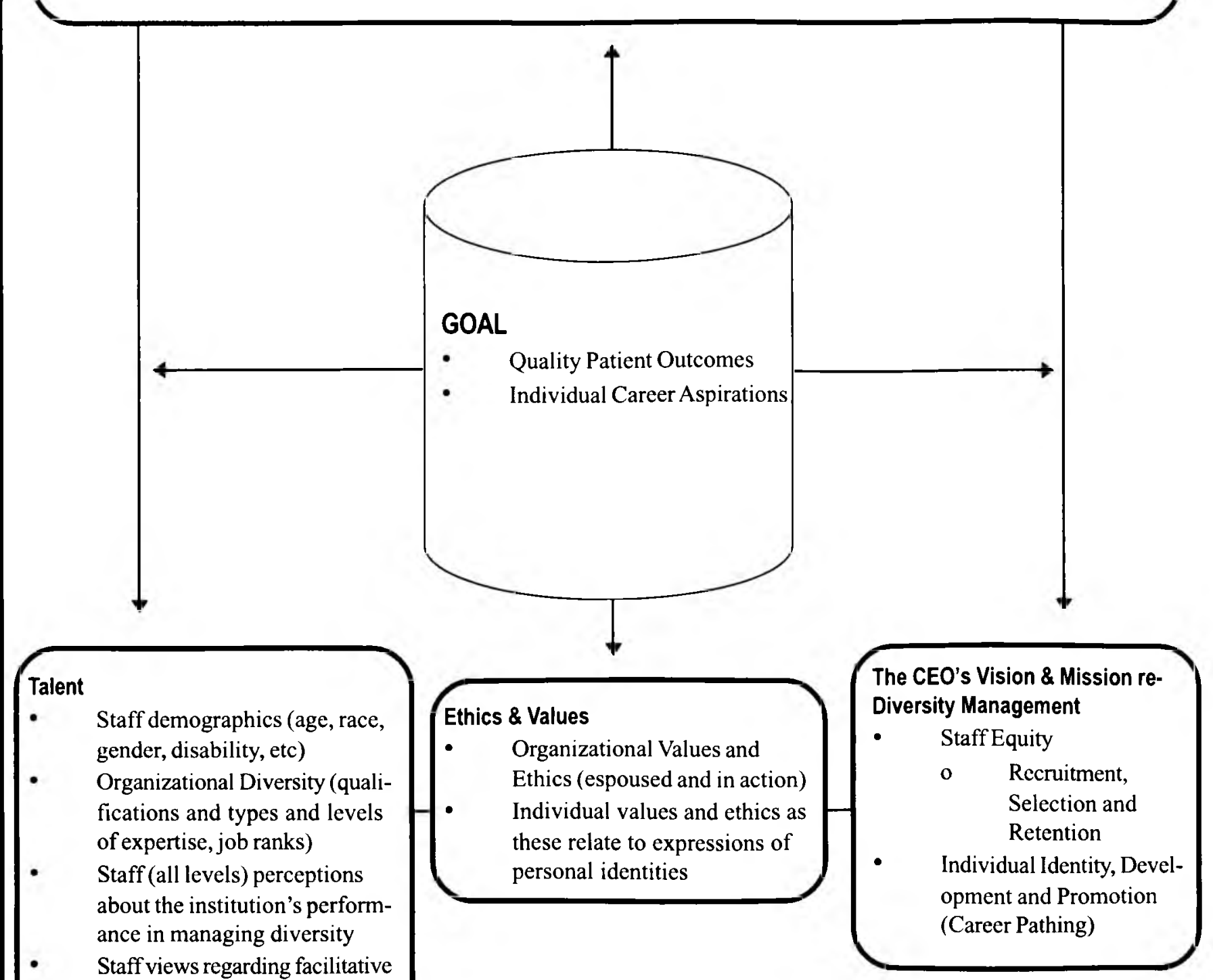


Friday \& Friday 2003: 863-880) a broad strategy of intervention aimed at longterm solution, rather than immediate problem solving is what is presented in this paper.

The significance of strategically positioning diversity management as part of the institution's strategic direction cannot be over emphasized. Unless diversity management is elevated to the level of the institution's strategic direction, no one in the institution, including the line managers and staff whose responsibility it will be to ensure that the institution's strategy is translated into action, will see it as important. Senior management must be seen to lead the process. In my view this is not the time to use a consultant, or if one is used, it must be made very clear that the consultant's role is to facilitate and that the role of the CEO is to lead the strategy development work. Ideally, this should be part of the institution's strategy development process, i.e. the diversity development strategy should not be a stand-alone activity.

\section{Setting the Context and Creating Space for Constructive Engagement}

It is the senior management's responsibility to set the context. It is not enough that the CEO's leadership team (direct reports) is aware of legislated requirements for diversity. The $\mathrm{CEO}$ has to ensure that all those with whom he/she expects to chart the course and thus facilitate and monitor implementation, start from the same frame of reference. Critical engagement with the contextual issues is essential. Figure 1 depicts some of the issues and/or arcas of discussion that could be used to create a framework for effective participation and dialogue. An analysis of the context focusing on macro-level arguments, the organization's internal current situation, as this relates to staff profile, ethics and values and the CEO's vision and mission for diversity management at the institution creates a useful point of departure.

At the macro-level an analysis of the context should include a discussion on the policy regulatory framework that governs affirmative action and employment equity, including interpersonal and professional working relation- ships, the regional, national and global contexts and their impact on the health industry's competition for health personnel. The opportunities presented by a facilitative regulatory environment should provide an avenue for an open and transparent discussion on the subject. An analysis of the institution's current situation should include a broad and in-depth presentation and discussion of the socio-demographics of the people who populate the institution: both staff and patient demographics. With regard to staff profile, the discussion must go beyond the numbers to include presentations on staff perceptions of the institution's performance in diversity management as well as their views regarding the factors that are seen as either facilitating or hindering the institution's effective management of diversity. Ethics and values convey to the public and the internal stakeholders, the standards that delineate acceptable behaviours and interactions within the institution (CIPD 2005: 38). Critical discourse on these and other issues creates an opportunity for the whole leadership team to make meaning of the context within which they are expected to work and should result in the acceptance of change as inevitable and that a "business as usual" attitude is no longer an option. This session should end with the presentation of the CEO's vision for diversity management. This vision has to be a bold and clear statement of what the CEO aspires to for the institution's diversity profile, both in character and quality. Ultimately, the goal is to create an environment conducive to attainment of quality patient outcomes and individual career aspirations.

\section{Determining Key Strategic Areas of Intervention}

Having arrived at a point where there is a common understanding and acceptance that something has to be done about the way in which the institution manages diversity, the strategy development process would be ready to proceed to deliberations aimed at deciding on key strategic areas of intervention. The leadership team will have to champion the strategy as well as oversee its implementation within their respective divisions. At this critical stage of the process, the aim is to develop an agreed upon diversity management strategy. Real engagement is therefore critical. The resultant institutional diversity management strategy should be based on a collectively agreed upon direction for the institution. This could include a number of areas such as policy development and/or review, institutionalization strategy, recruitment and retention processes, education and training, implementation and monitoring. Essentially, the institution's diversity management strategic plan must be based on short and long-term targets, with clear indicators and time frames that the institution's leadership team (senior management) has agreed upon.

The senior managers then have a responsibility to drive the process of dissemination and rally around the strategy to obtain acceptance within their respective divisions.

\section{Implementation and Monitoring}

It is essential that the strategic plan does not become merely a glossy publication for distribution to visitors. Implementation is the key to success. Developing annual operational plans against which progress can be monitored, is critical to success. An operational plan is invaluable in ensuring that the front line staff and middle managers stay focused on the agreed upon objectives toward attaining the institution's goals for becoming a diversity oriented organization. The plan must be characterized by an unambiguous and clear policy statement about the organization's standpoint about all forms discrimination, disrespect, and harassment. There must be clear and unambiguous statements about ethical and professional interpersonal relationships and significance of each individual's contribution to the institution's efforts towards attaining its goals.

Most importantly, managing diversity must be a mainstream issue, owned by everyone. Essential to the implementation process is ensuring that (a) periodic review of progress is conducted, (b) diversity management strategic interventions are supported through resource allocation, and (c) individual performance of all managers is in alignment with the institution's diversity strategic goals. As noted elsewhere (Gwele 2008: 329) it is imperative that 
timelines for progress review be established very early in the planning process. The review meetings should create space for an honest appraisal of each division's progress toward attainment of its objectives as well as sharing of plans for corrective action where indicated.

The CEO's role at operational level should focus on helping departments access the resources they require in order to implement their division's planned interventions. Supporting line managers in the decisions they take, which admittedly will most often be contested, is critical in ensuring that line managers feel safe in taking bold actions toward the attainment of the institution's diversity goals.

Building an accountability system through performance appraisal signals the seriousness with which the institution views diversity management. It is the CEO's responsibility to drive the institution's diversity management project through his/her leadership team. Individual performance, of the line managers has to be measured against mutually agreed upon indicators of performance as explicitly stated in each division's diversity strategic plan. Being cognizant of the contentious nature of performance appraisal, especially within a unionized workplacc, "where no formal agreements have been made with the institution's labour unions, it is important that performance appraisal focuses only on individual staff development toward optimum performance and thus places emphasis on identifying and suggesting alternative strategies for corrective action and improvement toward achieving agreed upon institutional goals rather than linking it with summative decisions regarding people's employment status "(Gwele 2008: 330).

\section{Conclusion}

In conclusion, I would like to acknowledge that, as a manager I have spent a number of years focusing on ensuring representation without paying much attention to the development and harnessing of individual talent and potential. The results are glaring. Improvement in demographic representation has been achieved and the represented but previously disadvantaged groups remain in lower ranks, with only one or two in management or senior positions. I believe it is time to pay attention to a number of leading authors (de Leon Saintz 2008: 167; Thomas 2006: 45-49) in the field and deal with diversity management as a holistic institutional management strategy. Admittedly, leading and managing diversity is always going to be uncomfortable and as noted by Thomas (2006: 47 ) one of the requisite skills for future diversity management leaders, is in "being comfortable with being uncomfortable". Of course numbers do count, if only to ensure that there is a diverse workforce to manage, without which, one cannot claim to be leading and managing a transformed workspace and/or environment.

\section{Acknowledgements}

This is a modified version of a paper presented at the $2^{\text {nd }}$ Biannual Nursing Managers' Summit 2007; held in Sandton, Johannesburg in October 2007. Hosted by: A.M.C. International

\section{References}

AYTON-SHENKER, D 1995: The challenge of human rights and cultural diversity. United Nations Department of Public Information. Geneva: DPI/1627/ HR.

ARIES, N 2004: Managing diversity: the differing perceptions of managers, line workers and patients. Health care management review. 29(3): 172-180.

\section{CHARTERED INSTITUTE OF PER-} SONNEL DEVELOPMENT (CIPD)

2005: Managing diversity: People make the difference at work- but everyone is different. London: CIPD.

FITZGERALD, TK 1997: Understanding diversity in the workplace: cultural metaphors or metaphors of identity? Business horizons. 1-3, July-August.

FRIDAY, E \& FRIDAY, SS 2003: Managing diversity using a strategic planned change approach. The Journal of management development. 22(10): 863-880.

GREEN, KA; LOPEZ, M; WYSOCKI, A \& KEPNER, K 2002: Diversity in the workplace: benefits, challenges, and the required managerial tools. Florida: Department of Food and Resource Economics, Institute of Food and Agricultural Sciences, University of Florida, Gainesville, FL. Available on http:// cdis.ifas.ufl.edu. Accessed on 5 September 2007.

GWELE, NS 2003: Globalization and the nursing workforce: The importance of what we care about. (An inaugural paper presented at the University of Natal: Durban, September 2003).

GWELE, NS 2008: Participative leadership in managing a faculty strategy. South African journal of higher education 22(2):322-332.

HUMAN, L 1996: Managing workforce diversity: A critique and example from a South Africa. International journal of manpower, 17(4-5): 46-64.

INSTITUTE FOR SCIENTIFIC INFORMATION (ISI). NOVEMBER, 1982: This week's citation classic. Current contents. 45: 20.

DE LEON SAINTZ, ML 2008: Leading change in diversity and cultural competence. Journal of professional nursing. 24(3): 167-171

SACHT, J n.d. Diversity in the workplace: how much progress has becn made? http://www.workinfo.com/ free/diversity.htm. Accessed 5 September 2007 .

THOMAS, RR 2006: Diversity Management: An essential craft for leaders. Leadership processes and practices. 45 49 , Summer.

TSHIKWATAMBA, NE FALL, 2003: The challenge of managing diversity in South Africa. The public manager. 36-38, Fall.

UNITED NATIONS-GENERALASSEMBLY, 1985: policies of apartheid of the Government of South Africa. Fortieth Session 40/60: 32-41. 